\title{
Recent Evidence for Colorectal Cancer Prevention Through Healthy Food, Nutrition, and Physical Activity: Implications for Recommendations
}

\author{
Prescilla S. Perera • Rachel L. Thompson • \\ Martin J. Wiseman
}

Published online: 10 January 2012

(C) Springer Science+Business Media, LLC 2012

\begin{abstract}
The aim of this paper is to present results from the World Cancer Research Fund/American Institute for Cancer Research (WCRF/AICR) Continuous Update Project on colorectal cancer and food, nutrition, and physical activity, an updated systematic literature review on evidence forming part of the 2007 WCRF/AICR Second Expert Report. Convincing evidence indicates that physical activity protects against colon cancer and that foods containing dietary fiber protect against colorectal cancer. Consumption of red meat and processed meat, ethanol from alcoholic drinks (by men and probably by women), as well as body fatness and abdominal fatness and the factors that lead to greater adult-attained height or its consequences are convincing causes of colorectal cancer. Consumption of garlic, milk, and calcium probably protects against this cancer. The updated evidence shows that food, nutrition, and physical activity have an important role in the causation and prevention of colorectal cancer.
\end{abstract}

Keywords Colorectal cancer Prevention - Bowel cancer . Food - Nutrition - Physical activity . Cancer prevention . Recommendations · Systematic reviews · Meta-analysis . Evidence · Continuous Update Project · Garlic · Milk · Calcium

\section{Introduction}

Colorectal cancer is the third most common type of cancer worldwide, with more than 1 million new cases diagnosed

P. S. Perera • R. L. Thompson • M. J. Wiseman $(\bowtie)$

World Cancer Research Fund,

Second Floor, 22 Bedford Square,

London WC1B 3HH England, UK

e-mail: m.wiseman@wcrf.org in 2008, accounting for $9.7 \%$ of all incident cancers [1]. Men accounted for 664,000 new cases and women 571,000 new cases. Incidence is highest in high-income countries such as those in North America and Western Europe but also in Asian countries that have experienced nutrition transition such as Japan, Singapore, and North Korea [1]. It remains relatively uncommon in Africa and much of Asia and is somewhat more common in men than in women. Nevertheless, although it can be successfully treated at early stages, it is fatal in just under one half of all cases and is the fourth most common cause of death from cancer.

Environmental and in particular diet and lifestyle factors are likely to be the main determinants of colorectal cancer risk, which is indicated by the rapid increase in colorectal cancer incidence in parallel with economic development and adoption of a Western lifestyle [2]. In the United Kingdom, one third of the most common cancers (mouth, pharynx, larynx, esophagus, lung, stomach, pancreas, gallbladder, liver, colorectum, breast, endometrium, prostate, and kidney) are estimated to be preventable through a healthy diet, being physically active, and maintaining a healthy weight. For colorectal cancer, the proportion of preventable cases is about $43 \%[3 \bullet \bullet]$.

\section{Second Expert Report and Recommendations}

The World Cancer Research Fund/American Institute for Cancer Research (WCRF/AICR) published its Second Expert Report, Food, Nutrition, Physical Activity and the Prevention of Cancer: A Global Perspective [4], in 2007, a comprehensive and systematic analysis of the evidence on the links between food, nutrition, physical activity, and risk of cancer, including colorectal cancer. This report of an independent panel of international experts shows the important role that food, nutrition, and physical activity have in 
the prevention and causation of colorectal cancer. It includes recommendations for cancer prevention:

1. Be as lean as possible without becoming underweight.

2. Be physically active for at least 30 min every day.

3. Avoid sugary drinks and limit consumption of energydense foods (particularly processed foods high in added sugar, low in fiber, or high in fat).

4. Eat more of a variety of vegetables, fruits, whole grains, and pulses.

5. Limit consumption of red meats and avoid processed meats.

6. If consumed at all, limit alcoholic drinks to $2 / \mathrm{d}$ for men and $1 / \mathrm{d}$ for women.

7. Limit consumption of salty foods and foods processed with salt (sodium).

8. Do not use supplements to protect against cancer.

9. It is best for mothers to breastfeed exclusively for up to 6 months and then add other liquids and foods.

10. After treatment, cancer survivors should follow the Recommendations for Cancer Prevention.

\section{The Continuous Update Project}

Since the Second Expert Report, WCRF/AICR have initiated the Continuous Update Project (CUP) in collaboration with a team at Imperial College London in order to keep the evidence updated into the future. An independent panel of experts comprising leading scientists in the fields of diet, physical activity, obesity, and cancer reviews the findings and draws conclusions based on the body of scientific evidence and when necessary will revise the $2007 \mathrm{WCRF} /$ AICR recommendations.

The CUP follows the same robust process as the Second Expert Report. The database of published journal articles is updated on a rolling basis from which at any point in time, the most current review of scientific data (including metaanalyses where appropriate) can be performed. All 17 cancer sites reviewed in the original Second Expert Report will be updated in the CUP database by 2015. From 2015 to 2017, the panel will formally review the recommendations from the Second Expert Report.

The goals of the CUP are as follows:

- Provide the scientific community with comprehensive and up-to-date evidence related to food, nutrition, physical activity, body weight, and cancer.

- Become a trusted source used by scientists, health professionals, and policy makers.

- Ensure WCRF/AICR education resources for health professionals and the general public are based on the most up-to-date evidence.
Herein we present the systematically reviewed evidence for colorectal cancer in relation to food, nutrition, and physical activity, updated with studies published since 2006, and the implications for the WCRF/AICR Cancer Prevention Recommendations.

\section{Methodology}

For the Second Expert Report, a series of specially commissioned systematic literature reviews (SLRs) covering 17 cancer sites, the determinants of obesity, and recommendations made by other authoritative reports also related to the prevention and control of other diseases formed the basis for the panel's judgements on the causal relationships between food, nutrition and physical activity, and cancer. The SLRs included evidence published up to the end of 2005 and principally included a combination of different types of epidemiologic evidence, mechanistic data, and (where available) randomized controlled trials.

The evidence in both the Second Expert Report and the CUP was graded based on the approach by Hill [5] to identify exposures (environment, including lifestyle factors) associated with disease that demonstrate evidence of causality that is strong enough to warrant action to address them. Recommendations were only made when the panel judged that there was sufficient evidence of causality (ie, that a factor either directly decreases or increases the risk of cancer) to justify making recommendations.

Based on the experience of conducting the SLRs for the Second Expert Report, some modifications to the methodology were made. The literature search was restricted to Medline. Retrospective case-control studies were only included in the reviews when insufficient data were available from prospective studies. The 2010 CUP-updated analysis for colorectal cancer included studies published up to December 2009 for all exposures, and for fruits, vegetables, red and processed meat, vitamin $\mathrm{D}$, alcohol, and height papers published up to May/June $2010[6 \bullet \cdot$. Where possible, studies were included in meta-analyses (Table 1). A summary of the conclusions is available [7••].

\section{Summary of Recent Evidence}

The updated evidence on colorectal cancer for exposures deemed convincing or probable is summarized in this section (Table 2 and Table 3), with a brief summary for exposures where evidence was more limited. A total of 516 papers are now included in the CUP database for colorectum 
Table 1 What is a meta-analysis?

-Study-level meta-analysis provides single estimates of effect using information from multiple studies of the same design. These summary estimates can provide evidence regarding the presence or absence of an association and examine possible dose-response relationships.

-Meta-analysis, often displayed graphically on a forest plot (Fig. 1), can also identify heterogeneity between studies. This heterogeneity can be quantified using a measure called $\mathrm{I}^{2}$, which ranges from $0 \%-100 \%$ and indicates the percentage of total variation across studies that is not due to chance. In general, an $\mathrm{I}^{2}$ of $\leq 25 \%$ indicates low heterogeneity, $\sim 50 \%$ indicates moderate heterogeneity, and $\geq 75 \%$ indicates high heterogeneity. The confidence interval (CI) is an indication of how much random error underlies the point estimate; it does not take into account confounding and other forms of systematic bias. A confidence level of $95 \%$ indicates a $95 \%$ probability that the true value falls within the CI.

-Random effects models are used to generate the forest plots. This type of model does not assume that the links between exposure and outcome are the same in different studies.

(253 from the Second Expert Report and 263 from the CUP); these form the basis of this report.

Table 2 Convincing and probable conclusions from the WCRF/AICR CUP on colorectal cancer

Food, nutrition, physical activity, and cancers of the colon and rectum

\begin{tabular}{|c|c|c|}
\hline & Decreases risk & Increases risk \\
\hline \multirow[t]{6}{*}{ Convincing } & Physical activity $^{\mathrm{ab}}$ & Red meat ${ }^{\mathrm{d}}$ \\
\hline & $\begin{array}{l}\text { Foods containing } \\
\text { dietary fiber }^{c}\end{array}$ & Processed meat ${ }^{\mathrm{e}}$ \\
\hline & & Alcoholic drinks (men) ${ }^{\mathrm{f}}$ \\
\hline & & Body fatness \\
\hline & & Abdominal fatness \\
\hline & & Adult-attained height ${ }^{\mathrm{g}}$ \\
\hline \multirow[t]{3}{*}{ Probable } & Garlic & Alcoholic drinks (women) ${ }^{\mathrm{f}}$ \\
\hline & Milk $^{\text {h }}$ & \\
\hline & Calcium $^{\mathrm{i}}$ & \\
\hline
\end{tabular}

${ }^{a}$ Physical activity of all types: occupational, household, transport, and recreational

${ }^{\mathrm{b}}$ The panel judges that the evidence for colon cancer is convincing; no conclusion was drawn for rectal cancer

${ }^{\mathrm{c}}$ Includes foods naturally containing the constituent and foods that have the constituent added; dietary fiber is contained in plant foods

${ }^{\mathrm{d}}$ The term red meat refers to beef, pork, lamb, and goat from domesticated animals

${ }^{\mathrm{e}}$ The term processed meat refers to meats preserved by smoking, curing, salting, or addition of chemical preservatives

${ }^{\mathrm{f}}$ The judgements for men and women are different because fewer data are available for women; for colorectal and colon cancers, the effect appears stronger in men than in women

${ }^{g}$ Adult-attained height is unlikely to modify the risk of cancer directly; it is a marker for genetic, environmental, hormonal, and nutritional factors affecting growth during the period from preconception to completion of linear growth

${ }^{\mathrm{h}}$ Milk from cows (most data are from high-income populations, in which calcium can be taken to be a marker for milk/dairy consumption); the panel judges that a higher intake of dietary calcium is one way in which milk could have a protective effect

${ }^{\mathrm{i}}$ The evidence is derived from studies using supplements at a dose of $1,200 \mathrm{mg} / \mathrm{d}$

CUP, Continuous Update Project; WCRF/AICR, World Cancer Research Fund/American Institute for Cancer Research

\section{Overweight and Obesity}

Excess energy from food and beverages is stored in the body as fat in adipose tissue. Since the 1980s, typical body compositions have changed, with a worldwide increase in average body fatness and in overweight and obesity. This change is most notable in high-income countries and in industrial and urban environments in many countries. In several low-income countries, high levels of body fatness exist alongside undernutrition in the same communities.

Body mass index (BMI) is most commonly used as an indirect marker for body fatness. The mechanisms through which body fatness could plausibly influence cancer risk are outlined in Table 4.

\section{Body Fatness}

The majority of the 29 studies for colorectal cancer showed increased risk with increased body fatness. Meta-analyses (per $\mathrm{kg} / \mathrm{m}^{2}$ increment) showed increased risks of $2 \%, 3 \%$, and $1 \%$ for colorectal, colon, and rectal cancers, respectively. They also showed a larger effect in men than women ( $4 \%$ vs $2 \%$ for colon cancer) (Table 5).

Two other published dose-response meta-analyses (per $\left.5 \mathrm{~kg} / \mathrm{m}^{2}\right)$ with a large number of cases $(>20,000$ for colon cancer for both men and women separately) showed a $24 \%$ increased risk for men and 9\% increased risk for women (20,975 cases from 19 studies) for colon cancer and 9\% increased risk for men (14,894 cases from 18 studies) and nonsignificant increased risk for women $(9,052$ cases from 14 studies) for rectal cancer $[8,9]$.

\section{Abdominal Fatness}

All studies showed increased risk with increased waist circumference (five studies) or increased waist-to-hip ratio (nine studies) and colorectal cancer. Similar results were shown for colon and rectal cancers.

Meta-analyses for waist circumference (per $2.54 \mathrm{~cm}$ ) for studies that did not adjust for BMI showed increased risks of $3 \%, 5 \%$, and $3 \%$ for colorectal, colon, and rectal cancers 
Table 3 Conclusions for convincing and probable exposures from the recent evidence on colorectal cancer

Abdominal fatness
Physical activity
Foods containing
dietary fiber

Garlic

Red meat

Processed meat

Milk

Alcoholic drinks (ethanol)

Dietary supplements

Adult-attained height

\section{Conclusions}

- There is abundant and consistent epidemiologic evidence of a clear dose-response relationship, and evidence for plausible mechanisms that operate in humans.

- The evidence that greater body fatness is a cause of colorectal cancer is convincing

-There is ample consistent evidence from cohort studies of a clear dose-response relationship and robust evidence for mechanisms that operate in humans.

-The evidence that abdominal fatness is a cause of colorectal cancer is convincing.

-There is abundant epidemiologic evidence from prospective studies showing a lower risk of colorectal cancer with higher overall levels of physical activity, and there is evidence of a dose-response effect.

-The effect is strong for colon cancer; however, there is no evidence of an effect for rectal cancer. The effect is strong and consistent in men but less strong in women. There is plausible evidence for mechanisms operating in humans.

-The evidence that higher levels of physical activity, within the range studied, protect against colon cancer is convincing.

-There is substantial consistent evidence from cohort studies, together with a clear doseresponse relationship, supported by evidence for plausible mechanisms. The effect is apparent in men and women.

-Since the publication of the Second Export Report, the recent evidence has strengthened; foods containing dietary fiber convincingly decrease colorectal cancer risk.

-The evidence, though not copious and mostly from case-control studies, is consistent with a dose-response relationship. There is evidence for plausible mechanisms.

- Garlic probably protects against colorectal cancer.

-A substantial amount of data from cohort studies showed a dose-response relationship, supported by evidence for plausible mechanisms operating in humans.

-Consumption of red meat is a convincing cause of colorectal cancer.

-There is a substantial amount of evidence, with a dose-response relationship apparent from cohort studies. There is strong evidence for plausible mechanisms operating in humans.

- Consumption of processed meat is a convincing cause of colorectal cancer.

-The evidence on milk from cohort studies is reasonably consistent, supported by stronger evidence from dietary calcium as a marker. There is evidence for plausible mechanisms.

-Milk probably protects against colorectal cancer.

-There is ample and generally consistent evidence from cohort studies. A dose-response relationship is apparent. There is evidence for plausible mechanisms. For colorectal and colon cancer, the effect appears stronger in men than in women.

-Ethanol from alcoholic drinks is a convincing cause of colorectal cancer in men and probably a cause in women.

-There is generally consistent evidence on dietary calcium, total calcium (dietary and supplemental), and calcium supplements from cohort studies. The effect was apparent in men and women. There is evidence for plausible mechanisms.

- Calcium probably protects against colorectal cancer.

-There is ample epidemiologic evidence from cohort studies, which is consistent, and there is a clear dose-response relationship, with evidence for plausible mechanisms operating in humans.

-The evidence that the factors that lead to greater adult-attained height or its consequences are a cause of colorectal cancer is convincing. The causal factor is unlikely to be tallness itself, but rather factors that promote linear growth in childhood.
(Table 5), respectively, that were only slightly attenuated when adjusted for BMI. For colon cancer specifically, there was a $6 \%$ increased risk in men and a $3 \%$ increased risk in women (Table 5). Meta-analyses for waist-to-hip ratio (per 0.1 increment) showed a $17 \%, 27 \%$, and $20 \%$ increased risk for colorectal, colon, and rectal cancers, respectively (Table 5).

\section{Physical Activity}

The review included total physical activity as well as different types of activity, such as recreational and occupational. Eight of 10 studies on colon cancer reported a lower risk with increased total physical activity. Many studies were 
Table 4 Mechanisms for body fatness influencing cancer risk

-Body fatness directly affects levels of many circulating hormones, such as insulin, insulin-like growth factor-1, and estrogens, creating an environment that encourages carcinogenesis and discourages apoptosis.

-Insulin resistance is increased, in particular by abdominal fatness, and the pancreas compensates by increasing insulin production. This hyperinsulinemia increases the risk of cancers of the colon and endometrium, and possibly of the pancreas and kidney [24]. Adipose tissue is the main site of estrogen synthesis in men and postmenopausal women, and increased body fatness results in increased estradiol in men and women and may also result in higher testosterone levels in women (extreme obesity can lead to polycystic ovary disease) [24]. Increased levels of sex steroids are strongly associated with risk of endometrial and postmenopausal breast cancers $[25,26]$ and may impact on colon and other cancers.

-Obesity is characterized by a low-grade chronic inflammatory state. The adipocyte (fat cell) produces proinflammatory factors, and obese individuals have elevated concentrations of circulating tumor necrosis factor- $\alpha$ [24], interleukin-6, and C-reactive protein compared with lean people [27], as well as of leptin, which also functions as an inflammatory cytokine [28]. Such chronic inflammation can promote cancer development.

Table 5 Summary estimates for convincing and probable exposures for colorectal, colon, and rectal cancers

\begin{tabular}{|c|c|c|c|}
\hline \multirow[t]{2}{*}{ Exposure } & \multicolumn{3}{|l|}{ Summary relative risk estimates $(95 \% \mathrm{CI})$} \\
\hline & Colorectal cancer & Colon cancer & Rectal cancer \\
\hline \multirow[t]{3}{*}{ Body fatness, $B M I\left(\right.$ per $\left.\mathrm{kg} / \mathrm{m}^{2}\right)$} & $1.02(1.02-1.03) ; \mathrm{I}^{2}=60 \%(n=23)$ & $1.03(1.03-1.04) ; \mathrm{I}^{2}=68 \%(n=29)$ & $1.01(1.01-1.02) ; \mathrm{I}^{2}=14 \%(n=22)$ \\
\hline & M: $1.03(1.03-1.04) ; \mathrm{I}^{2}=0 \%(n=12)$ & M: $1.04(1.03-1.05) ; \mathrm{I}^{2}=50 \%(n=22)$ & M: $1.02(1.01-1.02) ; \mathrm{I}^{2}=0 \%(n=18)$ \\
\hline & $\mathrm{W}: 1.02(1.01-1.03) ; \mathrm{I}^{2}=67 \%(n=16)$ & $\mathrm{W}: 1.02(1.01-1.03) ; \mathrm{I}^{2}=53 \%(n=24)$ & $\mathrm{W}: 1.01(1.00-1.02) ; \mathrm{I}^{2}=32 \%(n=18)$ \\
\hline \multirow[t]{2}{*}{$\begin{array}{l}\text { Abdominal fatness/waist } \\
\text { circumference (per } 2.54 \mathrm{~cm})\end{array}$} & \multirow[t]{2}{*}{$1.03(1.02-1.04) ; \mathrm{I}^{2}=0 \%(n=3)$} & $\begin{array}{l}1.05(1.03-1.06) ; \mathrm{I}^{2}=63 \%(n=6) \\
\text { M: } 1.06(1.04-1.08) ; \mathrm{I}^{2}=53 \%(n=6)\end{array}$ & \multirow[t]{2}{*}{$1.03(1.01-1.04) ; \mathrm{I}^{2}=0 \%(n=3)$} \\
\hline & & $\mathrm{W}: 1.03(1.02-1.04) ; \mathrm{I}^{2}=49 \%(n=6)$ & \\
\hline Waist-to-hip ratio (per 0.1 increment) & $1.17(1.09-1.25) ; \mathrm{I}^{2}=0 \%(n=3)$ & $1.27(1.15-1.41) ; \mathrm{I}^{2}=0 \%(n=5)$ & $1.20(1.07-1.34) ; \mathrm{I}^{2}=0 \%(n=3)$ \\
\hline $\begin{array}{l}\text { Total physical activity } \\
\text { (for an increase of } 5 \mathrm{MET} \mathrm{h} / \mathrm{d} \text { ) }\end{array}$ & $0.97(0.94-0.99) ; \mathrm{I}^{2}=0 \%(n=3)$ & $0.92(0.86-0.99) ; \mathrm{I}^{2}=80 \%(n=5)$ & $1.02(0.95-1.10) ; \mathrm{I}^{2}=34 \%(n=3)$ \\
\hline $\begin{array}{l}\text { Recreational activity (for an increase } \\
\text { of } 5 \text { MET hour/week) }\end{array}$ & $0.97(0.94-1.00) ; \mathrm{I}^{2}=66 \%(n=3)$ & $0.98(0.96-1.00) ; \mathrm{I}^{2}=52 \%(n=5)$ & $1.00(0.97-1.03) ; \mathrm{I}^{2}=45 \%(n=5)$ \\
\hline \multirow{3}{*}{$\begin{array}{l}\text { Foods containing dietary fiber } \\
\text { (per } 10 \mathrm{~g} \text { dietary fiber/d) }\end{array}$} & $0.90(0.86-0.94) ; \mathrm{I}^{2}=4 \%(n=15)$ & $0.89(0.81-0.97) ; \mathrm{I}^{2}=35 \%(n=12)$ & $0.91(0.81-1.03) ; \mathrm{I}^{2}=15 \%(n=10)$ \\
\hline & M: $0.88(0.78-0.99) ; \mathrm{I}^{2}=35 \%(n=5)$ & M: $0.86(0.76-0.96) . \mathrm{I}^{2}=20 \%(n=7)$ & M: $0.90(0.69-1.19) ; \mathrm{I}^{2}=43 \%(n=5)$ \\
\hline & $\mathrm{W}: 0.92(0.87-0.98) ; \mathrm{I}^{2}=0 \%(n=10)$ & $\mathrm{W}: 0.94(0.82-1.08) ; \mathrm{I}^{2}=30 \%(n=8)$ & W: $0.91(0.76-1.08) ; \mathrm{I}^{2}=0 \%(n=6)$ \\
\hline \multirow[t]{2}{*}{$\begin{array}{l}\text { Red and processed meat } \\
\quad(\text { per } 100 \mathrm{~g} / \mathrm{d})\end{array}$} & $\begin{array}{l}1.16(1.04-1.30) ; \mathrm{I}^{2}=47 \%(n=9) \\
\text { M: } 1.08(0.84-1.39) ; \mathrm{I}^{2}=0 \%(n=2)\end{array}$ & $\begin{array}{l}1.21(1.06-1.39) ; \mathrm{I}^{2}=56 \%(n=7) \\
\text { M: } 1.41(0.98-2.03) ; \mathrm{I}^{2}=71 \%(n=2)\end{array}$ & \multirow[t]{2}{*}{$1.31(1.13-1.52) ; \mathrm{I}^{2}=18 \%(n=5)$} \\
\hline & $\mathrm{W}: 1.02(0.77-1.34) ; \mathrm{I}^{2}=61 \%(n=4)$ & $\mathrm{W}: 1.05(0.78-1.40) ; \mathrm{I}^{2}=57 \%(n=4)$ & \\
\hline \multirow[t]{2}{*}{ Red meat (per $100 \mathrm{~g} / \mathrm{d}$ ) } & $\begin{array}{l}1.17(1.05-1.31) ; \mathrm{I}^{2}=0 \%(n=8) \\
\text { M: } 1.28(0.49-3.35) ; \mathrm{I}^{2}=64 \%(n=2)\end{array}$ & $\begin{array}{l}1.12(0.97-1.29) ; \mathrm{I}^{2}=0 \%(n=9) \\
\text { M: } 1.06(0.75-1.50) ; \mathrm{I}^{2}=0 \%(n=2)\end{array}$ & \multirow[t]{2}{*}{$1.18(0.98-1.42) ; \mathrm{I}^{2}=0 \%(n=7)$} \\
\hline & $\mathrm{W}: 1.05(0.78-1.42) ; \mathrm{I}^{2}=22 \%(n=3)$ & W: $1.00(0.72-1.38) ; \mathrm{I}^{2}=0 \%(n=4)$ & \\
\hline \multirow[t]{2}{*}{ Processed meat (per $50 \mathrm{~g} / \mathrm{d}$ ) } & $\begin{array}{l}1.18(1.10-1.28) ; \mathrm{I}^{2}=12 \%(n=9) \\
\text { M: } 1.11(0.86-1.44) ; \mathrm{I}^{2}=35 \%(n=2)\end{array}$ & $\begin{array}{l}1.24(1.13-1.36) ; \mathrm{I}^{2}=0 \%(n=9) \\
\mathrm{M}: 1.64(0.94-2.84) ; \mathrm{I}^{2}=72 \%(n=3)\end{array}$ & \multirow[t]{2}{*}{$1.12(0.99-1.28) ; \mathrm{I}^{2}=0 \%(n=8)$} \\
\hline & W: $1.09(0.88-1.33) ; \mathrm{I}^{2}=0 \%(n=4)$ & $\mathrm{W}: 1.38(1.06-1.78) ; \mathrm{I}^{2}=0 \%(n=4)$ & \\
\hline \multirow[t]{2}{*}{ Milk (per 200 g/d) } & $\begin{array}{l}0.91(0.86-0.97) ; \mathrm{I}^{2}=0 \%(n=7) \\
\text { M: } 0.89(0.82-0.98) ; \mathrm{I}^{2}=0 \%(n=2)\end{array}$ & $\begin{array}{l}0.91(0.83-1.00) ; \mathrm{I}^{2}=25 \%(n=5) \\
\text { M: } 0.92(0.83-1.02) ; \mathrm{I}^{2}=26 \%(n=3)\end{array}$ & \multirow[t]{2}{*}{$0.98(0.82-1.17) ; \mathrm{I}^{2}=0 \%(n=3)$} \\
\hline & W: $0.94(0.85-1.04) ; \mathrm{I}^{2}=10 \%(n=5)$ & $\mathrm{W}: 1.01(0.87-1.17) ; \mathrm{I}^{2}=0 \%(n=2)$ & \\
\hline \multirow[t]{2}{*}{$\begin{array}{l}\text { Dietary calcium } \\
\left(_{(\text {per } 200 \mathrm{mg} / \mathrm{d})^{\mathrm{a}}}\right.\end{array}$} & $\begin{array}{l}0.94(0.93-0.96) ; \mathrm{I}^{2}=0 \%(n=13) \\
\text { M: } 0.93(0.88-0.99) ; \mathrm{I}^{2}=52 \%(n=3)\end{array}$ & $0.93(0.89-0.97) ; \mathrm{I}^{2}=10 \%(n=10)$ & \multirow[t]{2}{*}{$0.94(0.86-1.02) ; \mathrm{I}^{2}=35 \%(n=8)$} \\
\hline & W: $0.93(0.91-0.95) ; \mathrm{I}^{2}=0 \%(n=9)$ & & \\
\hline \multirow{3}{*}{$\begin{array}{l}\text { Ethanol in alcoholic drinks } \\
\text { (per } 10 \mathrm{~g} \text { ethanol/d) }\end{array}$} & $1.10(1.06-1.13) ; \mathrm{I}^{2}=51 \%(n=8)$ & $1.08(1.04-1.13) ; \mathrm{I}^{2}=60 \%(n=12)$ & $1.10(1.07-1.12) ; \mathrm{I}^{2}=0 \%(n=11)$ \\
\hline & M: $1.11(1.08-1.15) ; \mathrm{I}^{2}=21 \%(n=7)$ & M: $1.10(1.06-1.14) ; \mathrm{I}^{2}=62 \%(n=10)$ & M: $1.10(1.07-1.13) ; \mathrm{I}^{2}=6 \%(n=9)$ \\
\hline & $\mathrm{W}: 1.07(0.98-1.17) ; \mathrm{I}^{2}=0 \%(n=2)$ & W: $1.03(0.96-1.10) ; \mathrm{I}^{2}=34 \%(n=8)$ & W: $1.09(1.03-1.16) ; \mathrm{I}^{2}=0 \%(n=7)$ \\
\hline \multirow{3}{*}{$\begin{array}{l}\text { Adult-attained height } \\
\text { (per } 5 \mathrm{~cm})\end{array}$} & $1.05(1.03-1.08) ; \mathrm{I}^{2}=11 \%(n=8)$ & $1.09(1.05-1.12) ; \mathrm{I}^{2}=42 \%(n=9)$ & $1.03(0.99-1.07) ; \mathrm{I}^{2}=25 \%(n=8)$ \\
\hline & M: $1.04(1.03-1.06) ; \mathrm{I}^{2}=0 \%(n=6)$ & M: $1.08(1.03-1.13) ; \mathrm{I}^{2}=56 \%(n=7)$ & M: $1.05(1.01-1.08) ; \mathrm{I}^{2}=0 \%(n=7)$ \\
\hline & $\mathrm{W}: 1.06(1.04-1.09) ; \mathrm{I}^{2}=16 \%(n=5)$ & $\mathrm{W}: 1.09(1.06-1.13) ; \mathrm{I}^{2}=0 \%(n=7)$ & $\mathrm{W}: 1.00(0.95-1.06) ; \mathrm{I}^{2}=20 \%(n=6)$ \\
\hline
\end{tabular}

${ }^{\text {a }}$ Meta-analyses were not conducted for garlic and calcium supplements

BMI, body mass index; CI, confidence interval; M, men; MET, metabolic equivalent task; W, women 
unsuitable for meta-analysis due to the disparate measures used to assess physical activity.

Meta-analyses for total physical activity (for an increase of 5 metabolic equivalent tasks [MET] h/d) showed a $3 \%$ decreased risk of colorectal cancer and an $8 \%$ decreased risk of colon cancer (Table 5). For recreational activity (for an increase of $5 \mathrm{MET}$ hour/ week), summary estimates from meta-analyses were in the direction of decreased risk of colorectal and colon cancers but did not reach statistical significance (Table 5), whereas meta-analyses per $30 \mathrm{~min} / \mathrm{d}$ showed an $11 \%$ decreased risk of colorectal and a $12 \%$ decreased risk of colon cancer. The data also suggested that the effect was less for rectal cancer $[6 \bullet \bullet]$.

A published meta-analysis of highest versus lowest comparisons of leisure time physical activity and colon cancer showed a $20 \%$ decreased risk in men (10 studies) and 14\% decreased risk in women ( 9 studies) for colon cancer. A nonsignificant increased risk was found for rectal cancer [10].

Sustained moderate physical activity raises the metabolic rate and increases maximal oxygen uptake. In the long term, regular periods of such activity increase the body's metabolic efficiency and capacity (the amount of work that it can perform) and thus have a beneficial effect on body fatness. In addition, physical activity may protect against colon cancer by decreasing inflammation and reducing insulin levels and insulin resistance [4].

\section{Patterns of Diet}

The evidence is reviewed under the headings of plant foods, animal foods, alcoholic drinks, and dietary supplements.

\section{Plant Foods}

Foods Containing Dietary Fiber Dietary fiber is the residue of plant foods that is undigested in the small bowel and reaches the large bowel, where it is fermented by the colonic flora. It is characterized principally by its content of nonstarch polysaccharides and is found in vegetables, fruits, pulses (legumes), whole grain cereals, roots, tubers, and plantains. Thirteen of 18 studies for colorectal cancer showed decreased risk with increased intake of total dietary fiber.

Meta-analyses (per $10 \mathrm{~g} / \mathrm{d}$ ) showed a 10\% lower risk for colorectal cancer and an 11\% lower risk for colon cancer (Table 5 and Fig. 1). The summary estimates for rectal cancer were in the direction of decreased risk but did not reach conventional levels of statistical significance (Table 5) $[6 \bullet \bullet]$.

Meta-analyses (per $10 \mathrm{~g} / \mathrm{d}$ ) showed a 12\% decreased risk for men and an $8 \%$ decreased risk for women for colorectal cancer (Table 5). Adjustment for folate intake had little effect on the summary estimates.

Meta-analyses for sources of fiber and colorectal cancer showed a $10 \%$ decreased risk for cereal fiber; summary estimates for other sources of fiber were in the direction of

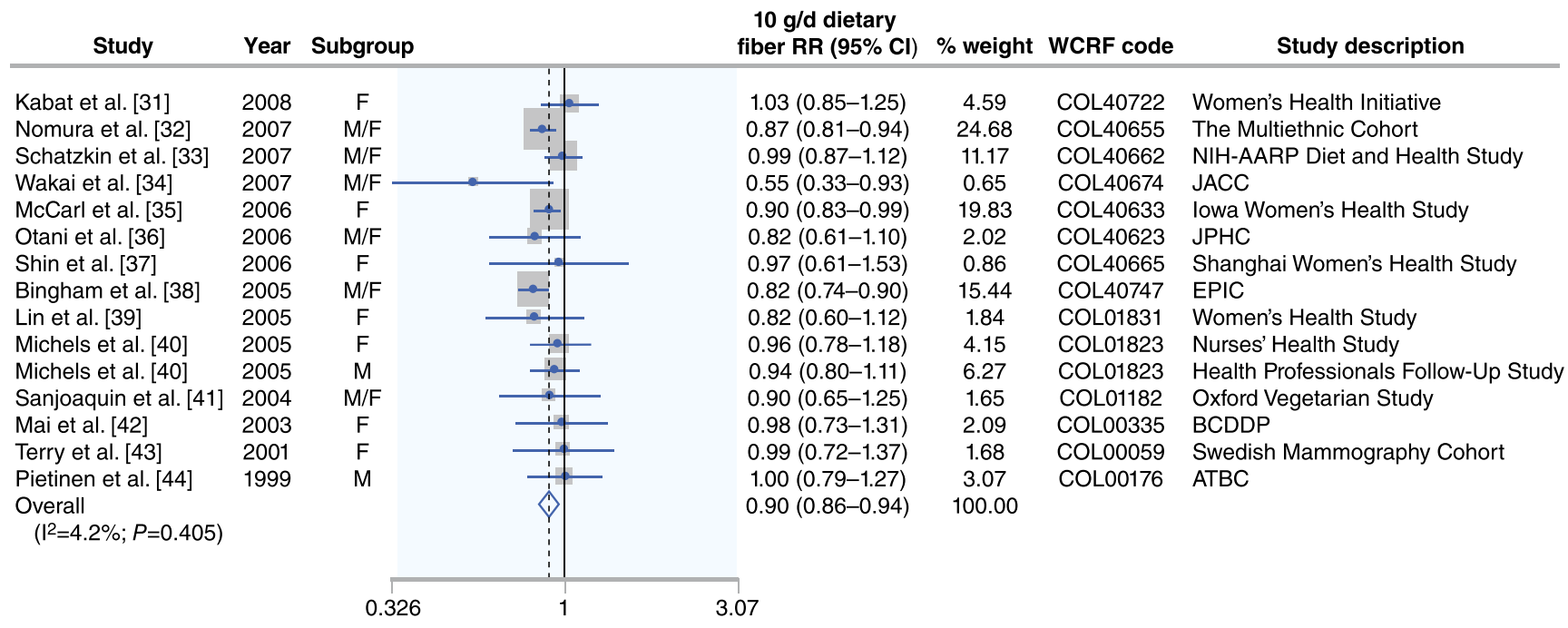

Note: Weights are from random effects analysis

Fig. 1 Dose-response meta-analysis of dietary fiber and colorectal cancer per $10 \mathrm{~g} / \mathrm{d}$. This figure presents the results of the dose-response meta-analysis of dietary fiber and colorectal cancer of 15 included studies. Most of the studies' point estimates are to the left of the "noeffect-on-risk" line. The confidence interval (CI) for studies crossing the "no-effect-on-risk" line indicates that the estimates are not statistically significant. The study giving the most weighting (influence) is Nomura et al. [32] (24.68\%), shown by the size of the square around the point estimate. Of all the studies presented, four are significant, suggesting a protective effect of fiber on colorectal cancer (that is, it has a relative risk $[R R]<1.00)$. F, female; M, male; WCRF, World Cancer Research Fund 
decreased risk but did not reach statistical significance $[6 \bullet \bullet]$. For whole grains, there was a $21 \%$ decreased risk per 3 servings/d for colorectal cancer and a $16 \%$ decreased risk for colon cancer [6*•]. A published pooled analysis of 8,100 colorectal cancer cases among 730,000 participants, followed up for 6 to 20 years, showed a nonsignificant decreased risk for the groups that consumed the most dietary fiber [11].

Fiber exerts several effects in the gastrointestinal tract, but the precise mechanisms for its probable protective role are still not clearly understood. Fiber dilutes fecal content, decreases transit time, and increases stool weight. The gut flora produce fermentation products, especially short-chain fatty acids, from a wide range of dietary carbohydrates and mucins that reach the colon. Short-chain fatty acids such as butyrate induce apoptosis, cell cycle arrest, and differentiation in experimental studies. Fiber intake is also strongly correlated with intake of folate, though adjusting for this often does not affect the risk reduction attributed to fiber [4].

Garlic No new cohort studies were identified as part of the CUP. Two cohort studies and six case-control studies identified as part of the Second Expert Report investigated garlic. All studies reported decreased risk with increased intake, with none reporting contrary results. Most studies did not reach statistical significance, and meta-analysis was not possible.

Considerable preclinical evidence with model carcinogens and transplantable tumors supports an anticancer effect of garlic and some of its allyl sulfur components. Animal studies demonstrate that allyl sulfides effectively inhibit colon tumor formation and also can inhibit cell growth in laboratory experiments [12-15].

\section{Animal Foods}

Red and Processed Meat Red meat includes beef, lamb, and pork, and processed meat includes red meat that has been preserved by smoking, curing, salting, or adding other chemical preservatives. Nine of 10 studies on colorectal cancer showed increased risk with higher intake. Metaanalyses (per $100 \mathrm{~g} / \mathrm{d}$ ) for colorectal, colon, and rectal cancers showed $16 \%, 21 \%$, and $31 \%$ increased risks, respectively (Table 5).

A published meta-analysis of highest versus lowest intakes of red and processed meat of 13,407 cases from 33 risk estimates showed a significant increased risk $(21 \%$ for colorectal cancer) [16]. A published dose-response metaanalysis of 7,367 cases from 14 studies showed a $28 \%$ increased risk per $120-\mathrm{g} / \mathrm{d}$ increase in red and processed meat [17].
Red meat. Nine of 12 studies for colorectal cancer showed increased risk with higher intake. Meta-analysis (per $100 \mathrm{~g} / \mathrm{d}$ ) showed a $17 \%$ increased risk for colorectal cancer (Table 5). Summary estimates were in the direction of increased risk of colon and rectal cancers but did not reach statistical significance (Table 5).

There are several potential underlying mechanisms for a positive association of red meat consumption with colorectal cancer. Red meat contains haem, which promotes the formation of potentially carcinogenic $N$-nitroso compounds, as well as cytotoxic alkenals from fat peroxidation. Red meat cooked at high temperatures results in the production of heterocyclic amines and polycyclic aromatic hydrocarbons that can cause colon cancer in individuals with a genetic predisposition [4].

Processed meat. Ten of 13 studies for colorectal cancer showed increased risk with higher intake. Meta-analysis (per $50 \mathrm{~g} / \mathrm{d}$ ) showed an $18 \%$ increased risk for colorectal cancer and a $24 \%$ increased risk for colon cancer (Table 5). The summary estimate for rectal cancer was in the direction of increased risk but did not reach statistical significance (Table 5). Meta-analyses (per $50 \mathrm{~g} / \mathrm{d}$ ) showed a $38 \%$ increased risk for women and a $64 \%$ increased risk for men for colon cancer, though the results for men did not reach statistical significance (Table 5).

Heterogeneity was low and explained by the disparity in category definitions between studies as well as by improved adjustment for confounders in recent studies. A published meta-analysis of highest versus lowest intakes of processed meat of 13,471 cases from 30 risk estimates showed a $19 \%$ increased risk for colorectal cancer [16]. A published doseresponse meta-analysis of 10 studies showed a $10 \%$ increased risk of colorectal cancer for each $30 \mathrm{~g} / \mathrm{d}$ of processed meat consumed. The same study showed an increased risk of $16 \%$ for 20 studies in a meta-analysis of highest versus lowest intakes of processed meat [18].

Milk Eight of 10 cohort studies for colorectal cancer showed decreased risk with increased milk intake. Summary estimates for meta-analyses (per $200 \mathrm{~g} / \mathrm{d}$ ) showed a 9\% decreased risk for colorectal cancer and were in the direction of decreased risk for colon and rectal cancers but did not reach statistical significance (Table 5). These findings that milk consumption is associated with a reduction in colorectal cancer risk were recently published [19॰].

A published meta-analysis of highest versus lowest comparison of milk intake for 2,813 cases from 14 cohort studies showed a $10 \%$ decreased risk for colorectal/colon cancer and a nonsignificant decreased risk for rectal cancer [20]. A published pooled analysis of 4,992 cases among 534,536 participants, followed up for 6 to 16 years, showed a $15 \%$ decreased risk for the groups that drank the most milk, and a $14 \%$ decreased risk for the groups with the highest dietary calcium intake [21]. 
Sixteen of 17 cohort studies reported decreased risk of colorectal cancer with increasing dietary calcium intake. Meta-analyses for dietary calcium (per $200 \mathrm{mg} / \mathrm{d}$ ) showed decreased risks of $6 \%$ and $7 \%$ for colorectal and colon cancers, respectively (Table 5). The summary estimate for rectal cancer was in the direction of decreased risk for rectal cancer but did not reach statistical significance. Metaanalyses (per $200 \mathrm{mg} / \mathrm{d}$ ) for colorectal cancer showed a $7 \%$ decreased risk for both men and women when analyzed separately (Table 5).

Most of the evidence comes from Western countries, in which dietary calcium intake can be taken as a marker for dairy consumption. Any effect of milk in reducing colorectal cancer risk is likely to be mediated at least in part by calcium, which restrains cellular proliferation and promotes differentiation and apoptosis in healthy and tumor colorectal cells [22]. Milk includes many other bioactive constituents that may also play a role. The Second Expert Report also found that diets high in calcium probably increase the risk of prostate cancer, and for this reason, no recommendations were made for dairy foods.

\section{Alcoholic Drinks (Ethanol)}

All studies investigating alcohol as ethanol showed increased risk with increased intake for colorectal (8 studies) and colon cancers (12 studies). Meta-analyses (per $10 \mathrm{~g}$ ethanol/d) showed a $10 \%$ increased risk of colorectal and rectal cancers and an $8 \%$ increased risk of colon cancer (Table 5). Meta-analyses showed a greater effect in men than women for colorectal and colon cancers, with the results for colorectal cancer showing an $11 \%$ increased risk in men, compared with $7 \%$ for women (Table 5). A published pooled analysis of more than 4,600 colorectal cancer cases among more than 475,000 participants, followed up for 6 to 16 years, showed a $41 \%$ increased risk for the groups that drank the most alcohol [23].

There was some suggestion of a greater effect in men than in women, possibly because of the generally higher consumption of alcohol among men. Also, men and women may prefer different types of alcoholic drinks; there may be hormone-related differences in alcohol metabolism or in susceptibility to alcohol. Data also suggested a J-shaped dose-response relationship, with low intake being associated with lower risk compared with no intake [4].

Some metabolites of alcohol, such as acetaldehyde, are carcinogenic. There is also an interaction with smoking. Tobacco may induce specific mutations in DNA that are less efficiently repaired in the presence of alcohol. Alcohol may also function as a solvent, enhancing penetration of other carcinogenic molecules into mucosal cells. Additionally, the effects of alcohol may be mediated through the production of prostaglandins, lipid peroxidation, and the generation of free radical oxygen species. Lastly, high consumers of alcohol may have diets low in essential nutrients, making tissues susceptible to carcinogenesis [4].

\section{Dietary Supplements}

The Second Expert Report found that in trials of high-dose nutrient supplements, cancer incidence was variously increased or decreased in selected populations. Such studies do not relate to widespread use among the general population, in whom the balance of risks and benefits cannot be predicted confidently, and a general recommendation to consume supplements for cancer prevention might have unexpected adverse effects. Increasing consumption of the relevant nutrients through the usual diet is preferred.

Calcium Six of the seven studies for colorectal cancer reported decreased risk with calcium supplementation, and no meta-analyses were conducted. A published metaanalysis showed a $24 \%$ decreased risk with use of calcium supplements for colorectal/colon cancer [20]. A pooled analysis of 4,992 cases among 534,536 participants, followed up for 6 to 16 years, showed a $22 \%$ decreased risk for the groups with the highest calcium intakes (dietary and supplemental sources) [21]. In addition, two randomized controlled trials and four cohort studies investigated calcium supplements and the risk of adenomas. Both trials and most of the cohort studies showed decreased risk with supplementation.

Calcium from diet is an important nutrient; intracellular calcium is a pervasive second messenger acting on many cellular functions, including cell growth. Calcium restrains cellular proliferation and promotes differentiation and apoptosis in healthy and tumor colorectal cells [22].

\section{Life Course: Adult-Attained Height}

Six of the eight cohort studies for colorectal cancer showed increased risk with increased height. Meta-analyses (per $5 \mathrm{~cm}$ ) showed a 5\% and 9\% increased risk for colorectal and colon cancers, respectively (Table 5). The summary estimate for rectal cancer was in the direction of increased risk but did not reach statistical significance (Table 5). For both colorectal and colon cancers, the increased risk was observed in both men and women; however, for rectal cancer, it was only statistically significant in men (Table 5).

The general mechanisms through which the factors that lead to greater adult attained height or its consequences could plausibly influence cancer risk are outlined in the Second Expert Report [4]. Many of these, such as early- 
Table 6 Foods containing vitamin D

-Two recent papers have now been included in the Continuous Update Project (CUP) database looking at dietary vitamin D. This includes one from the European Prospective Investigation into Cancer and Nutrition (EPIC) and one from the Japan Public Health Center-based Prospective Study on Cancer and Cardiovascular Diseases [29, 30].

-The evidence suggesting that vitamin D or foods containing it protect against colorectal cancer is limited, but it is important to highlight that the effects of vitamin D and calcium are strongly interrelated. This is because both are growth restraining and both induce differentiation and apoptosis in intestinal cells, and calcium-mediated effects are strongly dependent on vitamin D levels.

-Data from observational studies are probably hampered by the fact that total levels of the biologically active form are not only dependent on diet but also on supplements and UV exposure of the skin. Serum/plasma 25-hydroxyvitamin D status is therefore considered a more accurate measure of vitamin D status than vitamin D intake.

-It is important to be aware of the mechanistic effects of vitamin D polymorphism, as evidence shows that this could have an effect on susceptibility to colorectal cancer risk. The recent EPIC study included a meta-analysis looking at various polymorphisms, although no significant associations were noted [29].

life nutrition, altered hormone profiles, and the rate of sexual maturation, could plausibly increase cancer risk.

\section{Other Exposures}

The evidence that nonstarchy vegetables, fruits, and foods containing vitamin D protect against colorectal cancer and that cheese or foods containing iron, animal fats, or sugars are causes of this cancer is too limited to make recommendations. Evidence for foods containing folate, fish, and selenium is more limited, and no conclusion could be drawn. For more information on foods containing vitamin D, nonstarchy vegetables, and fruits, see Tables 6 and 7 .

\section{Conclusions}

In total, 263 new papers were identified between 2006 and 2010. The strongest evidence, corresponding to judgements of "convincing" and "probable," shows that physical activity protects against colon cancer and foods containing dietary fiber protect against colorectal cancer. The evidence also shows that consumption of red meat and of processed meat, ethanol from alcoholic drinks (by men and probably by women), as well as body fatness and abdominal fatness and the factors that lead to greater adult-attained height or its consequences are convincing causes. Consumption of garlic, milk, and calcium are probably protective. The evidence that nonstarchy vegetables, fruits, and foods containing vitamin $\mathrm{D}$ protect against colorectal cancer and that cheese or foods containing iron, animal fats, or sugars are causes of this cancer is too limited to make recommendations. Evidence for foods containing folate, fish, and selenium is more limited, and no conclusion could be drawn.

The recent evidence presented here shows that food, nutrition, and physical activity have an important role in the prevention and causation of colorectal cancer, supporting WCRF/AICR Recommendations for Cancer Prevention. Health professionals have a direct and obvious influence on people's health. Clinicians in particular are trusted by the public and are expected to give advice and guidance on good health and well-being and the prevention of disease, as well as diagnosis and treatment of disorders and diseases. In their daily interactions with people, health professionals have unrivaled opportunities to provide information and encouragement in support of healthy ways of life [3••].

The aim for health professionals should be to conduct professional practice to realize the potential for promoting health, including cancer prevention. The Second Expert Report outlines public health goals designed to be used by health professionals as well recommendations for individuals. The WCRF/AICR 2009 Policy Report makes the following recommendations for health professionals $[3 \cdot \bullet]$ :

Table 7 Nonstarchy vegetables and fruits

\footnotetext{
- There is a substantial amount of evidence for nonstarchy vegetables and fruits, but it is too inconsistent and limited to show that they protect against colorectal cancer.

-Although this is the case, it must be noted that this is a wide and disparate food category, and many different plant food constituents could feasibly contribute to a protective effect of nonstarchy vegetables and fruits. It is difficult to unravel the relative importance of each constituent and it is likely that any protective effect may result from a combination of influences on several pathways involved in carcinogenesis. These include dietary fiber, folate, selenium, allyl sulfides, glucosinolates, dithiolethiones, indoles, coumarins, ascorbate, chlorophyll, and antioxidants (including flavonoids, carotenoids, phenols, and phytoestrogens).

-There is also evidence that nonstarchy vegetables and fruit are probably protective against other cancers (nonstarchy vegetables: mouth, pharynx, larynx, esophagus, and stomach; fruits: mouth, pharynx, larynx, esophagus, lung, and stomach).
} 
- Prioritize public health, including cancer prevention, quality food, nutrition, and physical activity, in core training, practice, and professional development.

- Take a lead in educating and working with colleagues, other professionals, and other actors to improve public health, including cancer prevention.

- Involve people as family and community members and take account of their personal characteristics in all types of professional practice.

Acknowledgments The authors wish to acknowledge the research team at Imperial College London (United Kingdom) who prepared the 2010 CUP Colorectal Cancer Report [6••] and are responsible for updating the CUP database, and the CUP Expert Panel for reviewing the evidence (for more information, please visit http:/www.wcrf.org/ cancer research/cup/index.php).

Disclosure No potential conflicts of interest relevant to this article were reported.

\section{References}

Papers of particular interest, published recently, have been highlighted as:

- Of importance

•• Of major importance

1. Ferlay J, Parkin DM, Steliarova-Foucher E. Estimates of cancer incidence and mortality in Europe in 2008. Eur J Cancer. 2010;46 (4):765-81.

2. Center MM, Jemal A, Smith RA, Ward E. Worldwide variations in colorectal cancer. CA Cancer J Clin. 2009;59(6):366-78.

3. - WCRF/AICR. Policy and Action for Cancer Prevention. Food, Nutrition, Physical Activity: A Global Perspective. Washington DC: AICR 2009. This report provides the policy recommendations and actions to be implemented for cancer prevention.

4. WCRF/AICR. Food, nutrition, physical activity and the prevention of cancer: a global perspective. 2007.

5. Hill AB. The environment and disease: association or causation? Proc R Soc Med. 1965;58:295-300.

6. •-WCRF/AICR. Systematic Literature Review Continuous Update Project Report: The Associations Between Food, Nutrition and Physical Activity and the Risk of Colorectal Cancer: Imperial College London. 2010. This report provides the recent evidence on colorectal cancer from the CUP.

7. • WCRF/AICR. Colorectal Cancer Report Summary 2010 Summary. Food, nutrition, physical activity: A global perspective. 2011. This report provides a summary on the recent evidence on colorectal cancer from the CUP.

8. Renehan AG, Tyson M, Egger M, et al. Body-mass index and incidence of cancer: a systematic review and meta-analysis of prospective observational studies. Lancet. 2008;371(9612):56978

9. Harriss DJ, Atkinson G, George K, et al. Lifestyle factors and colorectal cancer risk (1): systematic review and meta-analysis of associations with body mass index. Colorectal Dis. 2009;11 (6):547-63.

10. Harriss DJ, Atkinson G, Batterham A, et al. Lifestyle factors and colorectal cancer risk (2): a systematic review and meta-analysis of associations with leisure-time physical activity. Colorectal Dis. 2009;11(7):689-701.

11. Park Y, Hunter DJ, Spiegelman D, et al. Dietary fiber intake and risk of colorectal cancer: a pooled analysis of prospective cohort studies. JAMA. 2005;294(22):2849-57.

12. Xiao D, Lew KL, Kim YA, et al. Diallyl trisulfide suppresses growth of PC-3 human prostate cancer xenograft in vivo in association with Bax and Bak induction. Clin Cancer Res. 2006;12 (22):6836-43.

13. Chu Q, Lee DT, Tsao SW, et al. S-allylcysteine, a water-soluble garlic derivative, suppresses the growth of a human androgenindependent prostate cancer xenograft, CWR22R, under in vivo conditions. BJU Int. 2007;99(4):925-32.

14. Shukla Y, Kalra N. Cancer chemoprevention with garlic and its constituents. Cancer Lett. 2007;247(2):167-81.

15. Milner JA. Preclinical perspectives on garlic and cancer. J Nutr. 2006;136(3 Suppl):827S-31.

16. Huxley RR, Ansary-Moghaddam A, Clifton P, et al. The impact of dietary and lifestyle risk factors on risk of colorectal cancer: a quantitative overview of the epidemiological evidence. Int J Cancer. 2009;125(1):171-80.

17. Larsson SC, Wolk A. Meat consumption and risk of colorectal cancer: a meta-analysis of prospective studies. Int $\mathrm{J}$ Cancer. 2006;119(11):2657-64.

18. Alexander DD, Miller AJ, Cushing CA, Lowe KA. Processed meat and colorectal cancer: a quantitative review of prospective epidemiologic studies. Eur J Cancer Prev. 2010;19(5):328-41.

19. - Aune D, Lau R, Chan DS, et al. Dairy products and colorectal cancer risk: a systematic review and meta-analysis of cohort studies. Ann Oncol. 2011 May 26. This paper reviews the recent evidence from the CUP on dairy products and colorectal cancer risk.

20. Huncharek M, Muscat J, Kupelnick B. Colorectal cancer risk and dietary intake of calcium, vitamin $\mathrm{D}$, and dairy products: a metaanalysis of 26,335 cases from 60 observational studies. Nutr Cancer. 2009;61(1):47-69.

21. Cho E, Smith-Warner SA, Spiegelman D, et al. Dairy foods, calcium, and colorectal cancer: a pooled analysis of 10 cohort studies. J Natl Cancer Inst. 2004;96(13):1015-22.

22. Lamprecht SA, Lipkin M. Cellular mechanisms of calcium and vitamin $\mathrm{D}$ in the inhibition of colorectal carcinogenesis. Ann N Y Acad Sci. 2001;952:73-87.

23. Cho E, Smith-Warner SA, Ritz J, et al. Alcohol intake and colorectal cancer: a pooled analysis of 8 cohort studies. Ann Intern Med. 2004;140(8):603-13.

24. Calle EE, Kaaks R. Overweight, obesity and cancer: epidemiological evidence and proposed mechanisms. Nat Rev Cancer. 2004;4 (8):579-91.

25. Key T, Appleby P, Barnes I, Reeves G. Endogenous sex hormones and breast cancer in postmenopausal women: reanalysis of nine prospective studies. J Natl Cancer Inst. 2002;94(8):606-16.

26. Kaaks R, Lukanova A, Kurzer MS. Obesity, endogenous hormones, and endometrial cancer risk: a synthetic review. Cancer Epidemiol Biomarkers Prev. 2002;11(12):1531-43.

27. Rexrode KM, Pradhan A, Manson JE, et al. Relationship of total and abdominal adiposity with CRP and IL-6 in women. Ann Epidemiol. 2003;13(10):674-82.

28. Loffreda S, Yang SQ, Lin HZ, et al. Leptin regulates proinflammatory immune responses. FASEB J. 1998;12(1):57-65.

29. Jenab M, Bueno-de-Mesquita HB, Ferrari P, et al. Association between pre-diagnostic circulating vitamin $\mathrm{D}$ concentration and risk of colorectal cancer in European populations: a nested casecontrol study. BMJ. 2010;340:b5500.

30. Ishihara J, Inoue $\mathrm{M}$, Iwasaki $\mathrm{M}$, et al. Dietary calcium, vitamin D, and the risk of colorectal cancer. Am J Clin Nutr. 2008;88 (6):1576-83. 
31. Kabat GC, Shikany JM, Beresford SA, Caan B, Neuhouser ML, Tinker LF, et al. Dietary carbohydrate, glycemic index, and glycemic load in relation to colorectal cancer risk in the Women's Health Initiative. Cancer Causes Control. 2008;19(10):1291-8.

32. Nomura AM, Hankin JH, Henderson BE, Wilkens LR, Murphy SP, Pike MC, et al. Dietary fiber and colorectal cancer risk: the multiethnic cohort study. Cancer Causes Control. 2007;18(7):753-64.

33. Schatzkin A, Mouw T, Park Y, Subar AF, Kipnis V, Hollenbeck A, et al. Dietary fiber and whole-grain consumption in relation to colorectal cancer in the NIH-AARP Diet and Health Study. Am J Clin Nutr. 2007;85(5):1353-60.

34. Wakai K, Date C, Fukui M, Tamakoshi K, Watanabe Y, Hayakawa $\mathrm{N}$, et al. Dietary fiber and risk of colorectal cancer in the Japan collaborative cohort study. Cancer Epidemiol Biomarkers Prev. 2007;16(4):668-75.

35. McCarl M, Harnack L, Limburg PJ, Anderson KE, Folsom AR. Incidence of colorectal cancer in relation to glycemic index and load in a cohort of women. Cancer Epidemiol Biomarkers Prev. 2006;15(5):892-6.

36. Otani T, Iwasaki M, Ishihara J, Sasazuki S, Inoue M, Tsugane S. Dietary fiber intake and subsequent risk of colorectal cancer: the Japan Public Health Center-based prospective study. Int J Cancer. 2006;119(6):1475-80.

37. Shin A, Li H, Shu XO, Yang G, Gao YT, Zheng W. Dietary intake of calcium, fiber and other micronutrients in relation to colorectal cancer risk: Results from the Shanghai Women's Health Study. Int J Cancer. 2006;119(12):2938-42.
38. Bingham SA, Norat T, Moskal A, Ferrari P, Slimani N, ClavelChapelon $\mathrm{F}$, et al. Is the association with fiber from foods in colorectal cancer confounded by folate intake? Cancer Epidemiol Biomarkers Prev. 2005;14(6):1552-6.

39. Lin J, Zhang SM, Cook NR, Rexrode KM, Liu S, Manson JE, et al. Dietary intakes of fruit, vegetables, and fiber, and risk of colorectal cancer in a prospective cohort of women (United States). Cancer Causes Control. 2005;16(3):225-33.

40. Michels KB, Fuchs CS, Giovannucci E, Colditz GA, Hunter DJ, Stampfer MJ, et al. Fiber intake and incidence of colorectal cancer among 76,947 women and 47,279 men. Cancer Epidemiol Biomarkers Prev. 2005;14:842-9.

41. Sanjoaquin MA, Appleby PN, Thorogood M, Mann JI, Key TJ. Nutrition, lifestyle and colorectal cancer incidence: a prospective investigation of 10998 vegetarians and non-vegetarians in the United Kingdom. Br J Cancer. 2004;90(1):118-21.

42. Mai V, Flood A, Peters U, Lacey Jr JV, Schairer C, Schatzkin A. Dietary fibre and risk of colorectal cancer in the Breast Cancer Detection Demonstration Project (BCDDP) follow-up cohort. Int J Epidemiol. 2003;32(2):234-9.

43. Terry P, Giovannucci E, Michels KB, Bergkvist L, Hansen H, Holmberg L, et al. Fruit, vegetables, dietary fiber and risk of colorectal cancer. Journal of the National Cancer Institute. 2001;93(7):525-33.

44. Pietinen P, Malila N, Virtanen M, Hartman TJ, Tangrea JA, Albanes D, et al. Diet and risk of colorectal cancer in a cohort of Finnish men. Cancer Causes Control. 1999;10(5):387-96. 